\section{Kidney \\ Blood Pressure Research}

Kidney Blood Press Res 2018;43:1104-1112

DOI: $10.1159 / 000491566$

Published online: 9 July, 2018

Accepted: 27 June, 2018

This article is licensed under the Creative Commons Attribution-NonCommercial-NoDerivatives 4.0 InternaThis article is licensed under the Creative Commons Attribution-NonCommercial-NoDerivatives 4.0 Interna-
tional License (CC BY-NC-ND) (http://www.karger.com/Services/OpenAccessLicense). Usage and distribution tor commercial purposes as well as any distribution of modified material requires written permission.

\title{
Clinical Outcome of Twice-Weekly Hemodialysis Patients with Long-Term Dialysis Vintage
}

\author{
Xinghui Lin Leyi Gu Mingli Zhu Miaolin Che Zanzhe Yu Hong Cai \\ Zhaohui Ni Weiming Zhang \\ Department of Nephrology, Renji Hospital, School of Medicine, Shanghai Jiao Tong University, \\ Shanghai, China
}

\section{Key Words}

Hemodialysis $•$ Dialysis frequency $\bullet$ Survival

\begin{abstract}
Background/Aims: Twice-weekly hemodialysis(HD) is prevalent in the developing countries, scarce data are available for this treatment in patients with long-term dialysis vintage. Methods: 106 patients with more than 5 years HD vintage undergoing twice-weekly HD or thriceweekly HD in a hemodialysis center in Shanghai between December 1, 2013 and December 31, 2013 were enrolled into the cohort study with 3 years follow-up. Kaplan-Meier analysis and Cox proportional hazards models were used to compare patient survival between the two groups. Subgroup analysis of 62 patients more than 10 years HD vintage was also performed according to their different dialysis frequency. Results: Compared with patients on thriceweekly HD, twice-weekly HD patients had significantly longer HD session time and higher single-pool Kt/ $\mathrm{V}$ (spKt/V) (session time, $4.59 \pm 0.45$ vs $4.14 \pm 0.31$ hours/per session, $\mathrm{P}<0.001$; spKt/V, $2.12 \pm 0.31$ vs $1.83 \pm 0.30, P<0.001$ ). Kaplan-Meier survival analysis indicated that the two groups had similar survival $(P=0.983)$. Multivariate Cox regression analysis showed that age and time-dependent serum albumin were predictors of patient mortality. Subgroup analysis of 62 patients more than 10 years HD vintage also indicated that the two groups had similar survival. During the follow-up, 4 patients dropped out from the twice-weekly HD group and transferred to thrice-weekly HD. Conclusion: The similar survival between twiceweekly HD and thrice-weekly HD in patients with long-term dialysis vintage is likely relating to patient selection, individualized treatment for dialysis patients based on clinical features and socioeconomic factors remains a tough task for the clinicians.
\end{abstract}




\section{Kidney Blood Pressure Research}

Lin et al.: Twice-Weekly Hemodialysis

\section{Introduction}

End-stage renal disease(ESRD) has caused heavy economic burden to both patients and governments. Hemodialysis(HD) is a major renal replacement therapy(RRT) for ESRD patients. For decades thrice-weekly HD has been established as a standard RRT for dialysis patients, but twice-weekly HD is prevalent in the developing countries, and occasionally could be spotted in the developed countries [1-3]. In China, about a quarter of the HD population receives twice-weekly HD [4], the proportion of this treatment regimen may be even higher in south Asia countries [5]. Few countries, such as Thailand, only twice-weekly HD could be covered by medical insurance [6]. Recently an incremental hemodialysis model with initiation of twice-weekly HD for incident patients has been advised in order to preserve the residual renal function better and to maximize the use of medical resource [7-9]. But it is unclear how long for this treatment approach could be lasted, and very scarce data are available for twice-weekly HD in patients with long-term dialysis vintage.

In the present study, we performed a retrospective cohort study with three years followup in Shanghai renji hospital hemodialysis center (western part), to evaluate the clinical outcome of twice-weekly hemodialysis patients with long-term dialysis vintage. All the patients have been more than 5 years HD vintage with regular twice-weekly HD or thriceweekly HD, 2 patients with twice-weekly HD and 3 patients with thrice -weekly HD have been more than 20 years vintage. This study was not a randomization controlled trial(RCT) as it was not suitable to conduct such a study in these special patients.

\section{Materials and Methods}

\section{Patient Selection and study design}

There were 180 patients undergoing regular hemodialysis between December 1, 2013 and December 31, 2013 in Shanghai Renji hospital hemodialysis center (western part). All the patients were dialyzed with Fresenius series dialyzers, most of them used high flux FX80 or FX1000. 118 patients have been more than 5 years HD vintage. 11 of them underwent hemodialysis with 2.5 times per week (i.e.,5 times HD for every 2 weeks), these patients were excluded from the study due to their irregular dialysis frequency, one patient was also excluded from the study because she was involved in a clinical trial. The rest of 106 patients with regular twice-weekly HD or thrice-weekly HD were eligible to be enrolled into the cohort study.

All patients were given informed consent. The hemodialysis modality was mainly based on patients'selfselection. Most of the patients selected twice-weekly HD due to financial constraints or inconvenient movement. Those who had suspected inadequate solute and/or fluid removal with twice-weekly HD were advised to transfer to thrice-weekly HD by physicians. The study protocol was in agreement with the guidelines of the Ethics Committee at our hospital.

Baseline data were recorded including age, gender, primary renal disease, dialysis frequency, duration on dialysis before enrollment, body surface area(BSA), body mass index(BMI), presence of diabetes mellitus (DM), blood pressure (BP), HD session time, biochemical indices, as well as spKt/V and ultrafiltration volume (values taken from Daugirdas formula for calculation of spKt/V). Urine status was also recorded according to patients' self-description. Most of the patients were receiving drugs common in ESRD, including antihypertensive medication, erythropoietin (EPO) and phosphorus binders.

Patients were regularly monitored, every six months there was a thorough examination of clinical parameters including virus test and other common biochemical indices and dialysis adequacy index, some biochemical indices such as hemoglobin and phosphorus level had more frequency monitor. Follow- up was ended until January 31, 2017. Death was the major end point. Patients who switched to the other dialysis frequency group (i.e., transfered from twice-weekly HD to thrice-weekly) were censored for survival analysis. 


\section{Kidney Blood Pressure Research}

Lin et al.: Twice-Weekly Hemodialysis

\section{Data Collection}

Adequacy of dialysis was estimated by measurement of spKt/V using Daugirdas formula [10]. URR was calculated as percentage of post-dialysis blood urea nitrogen (BUN) divided by pre-dialysis BUN. Weekly $\mathrm{Kt} / \mathrm{V}$ was counted as spKt/V multiplied by frequency/per week. Biochemical tests including hemoglobin, blood urea nitrogen, serum creatinine, glucose, calcium and phosphorus levels and intact parathyroid hormone (iPTH) were examined using automatic standard equipment. Fresenius TDMS software (Therapy data management system, V2.82.4593.33387) was used to assist with data management.

\section{Statistical analysis}

Statistical analysis was performed using SPSS 15.0 for Windows (SPSS Inc., Chicago, IL). Results were expressed as mean $\pm \mathrm{SD}$. Comparison of means or percentages were performed using paired and unpaired ANOVA or a Chi-square test. Correlations were analyzed using Pearson's correlation coefficient.

The Cox proportional hazards model was used for survival analysis. Baseline parameters with a $\mathrm{P}$ value $<0.05$ in univariate Cox regression were then incorporated into a final multivariate Cox regression analysis. Backward stepwise elimination using the Wald test was applied to remove insignificant variables, a $P$ value $<0.05$ was counted as statistical significance. Albumin was treated as a time-dependent variable in final Cox model.

We also performed Kaplan-Meier survival analysis, dividing the patients into two groups as twiceweekly HD or thrice-weekly HD. Subgroup analysis of survival in patients more than 10 years HD vintage was also performed according to their different dialysis frequencies.

\section{Results}

\section{Baseline characteristics}

In total 106 recruited patients, 38 of them underwent twice-weekly HD and 68 of them underwent thrice-weekly HD. 62 patients had been on HD for more than 10 years at enrollment (15 patients with twice-weekly HD and 47 patients with thrice-weekly HD), 2 patients with twice-weekly HD and 3 patients with thrice-weekly HD had been on HD for more than 20 years. The longest HD vintage was 24.9 years in this cohort, who was on twice-weekly HD.

Baseline characteristics of the subjects were summarized in Table 1. Briefly, compared to patients with thriceweekly HD, the twiceweekly HD patients had significantly longer HD session time and higher single-pool Kt/V (spKt/V) (session time, 4.59 \pm 0.45 vs $4.14 \pm 0.31$ hours/per session, $\mathrm{P}<0.001$; spKt $/ \mathrm{V}$, $2.12 \pm 0.31$ vs $1.83 \pm 0.30$, $\mathrm{P}<0.001)$. Weekly SpKt/V in twice-weekly HD group was significantly lower

Table 1. Baseline data of 106 HD-patients more than 5 years HD vintage grouped according to dialysis frequency. Note: Data are expressed as mean $\pm \mathrm{SD}, \mathrm{P}$ values result from comparisons of baseline values of the two groups divided by HD frequency. Abbreviations: BP, blood pressure; Scr, Serum creatinine; UF, ultrafiltration; SpKt/V, single-pool $\mathrm{Kt} / \mathrm{V}$; URR, urea reduction ratio; iPTH, intact parathyroid hormone

\begin{tabular}{lcccc}
\hline Characteristics & All Patients & $\begin{array}{c}\text { Twice-weekly } \\
\text { HD }\end{array}$ & Thrice-weekly HD & P Value \\
\hline No. of patients & 106 & 38 & 68 & \\
Gender M:F & $56: 50$ & $19: 19$ & $37: 31$ & \\
Age years & $60.1 \pm 12.5$ & $61.8 \pm 13.6$ & $59.1 \pm 11.8$ & 0.290 \\
HD vintage years & $11.4 \pm 4.7$ & $9.6 \pm 4.5$ & $12.4 \pm 4.6$ & 0.002 \\
$\geq 10$ years & $62(58.5)$ & $15(39.5)$ & $47(69.1)$ & \\
HD vintage,n(\%) & & & & \\
$\geq 20$ years & $5(4.7)$ & $2(5.3)$ & $3(4.4)$ & \\
HD vintage,n(\%) & $101(95.3)$ & $33(86.8)$ & $68(100)$ & \\
Anuric status, n(\%) & $13(12.3)$ & $3(7.9)$ & $10(14.7)$ & \\
Diabetic status, n(\%) & $1.66 \pm 0.17$ & $1.63 \pm 0.15$ & $1.68 \pm 0.18$ & 0.142 \\
Body surface area m ${ }^{2}$ & $23.0 \pm 3.3$ & $22.6 \pm 3.4$ & $23.2 \pm 3.2$ & 0.411 \\
Body mass index kg/m ${ }^{2}$ & $142.4 \pm 23.3$ & $151.0 \pm 21.6$ & $137.6 \pm 23.0$ & 0.004 \\
Systolic BP mmHg & $74.5 \pm 14.2$ & $74.3 \pm 16.1$ & $74.6 \pm 13.1$ & 0.913 \\
Diastolic BP mmHg & $28.7 \pm 6.6$ & $31.8 \pm 6.2$ & $27.0 \pm 6.3$ & 0.000 \\
Blood urea nitrogen mmol/L & $1040.8 \pm 221.3$ & $1114.3 \pm 287.0$ & $999.7 \pm 162.7$ & 0.010 \\
Scr umol/L & $1.93 \pm 0.33$ & $2.12 \pm 0.31$ & $1.83 \pm 0.30$ & 0.000 \\
SpKt/V & $78.4 \pm 5.5$ & $81.0 \pm 4.3$ & $77.0 \pm 5.6$ & 0.000 \\
URR \% & $5.03 \pm 1.01$ & $4.23 \pm 0.63$ & $5.48 \pm 0.90$ & 0.000 \\
Weekly SpKt/V & $4.30 \pm 0.42$ & $4.59 \pm 0.45$ & $4.14 \pm 0.31$ & 0.000 \\
HD session time hours & $3.11 \pm 0.91$ & $3.24 \pm 0.96$ & $3.04 \pm 0.88$ & 0.288 \\
UF rate L/per session & $58.8 \pm 10.4$ & $56.6 \pm 9.6$ & $60.0 \pm 10.8$ & 0.109 \\
Dry weight kg & $112.8 \pm 16.4$ & $109.2 \pm 15.7$ & $114.8 \pm 16.6$ & 0.094 \\
Hemoglobin g/L & $38.9 \pm 3.2$ & $39.2 \pm 3.0$ & $38.7 \pm 3.3$ & 0.452 \\
Serum albumin g/l & $2.23 \pm 0.33$ & $2.23 \pm 0.33$ & $2.24 \pm 0.34$ & 0.913 \\
Calcium mmol/L & $1.81 \pm 0.51$ & $1.90 \pm 0.46$ & $1.77 \pm 0.54$ & 0.217 \\
Phosphorus mmol/L & $573.6 \pm 515.1$ & $581.8 \pm 574.8$ & $569.0 \pm 482.9$ & 0.903 \\
iPTH pg/ml & & & & \\
\hline
\end{tabular}




\section{Kidney Blood Pressure Research}

than that in thrice-weekly HD $\operatorname{group}(\mathrm{P}<0.001)$. The two groups had similar age and albumin level, also ultrafiltration volume during HD session time between the two groups was similar. Subgroup analysis of 62 patients more than 10 years HD vintage also indicated similar results (Table 2).

5 patients in twiceweekly HD group with vintage between 5-10 years had urine output more than $200 \mathrm{ml}$ in the day prehemodialysis. None of the patients on thrice-weekly HD group or those with more than 10 years HD vintage had acceptable residual renal function(RRF).

\section{Longitudinal data}

Table 3 showed the longitudinal changes in biochemical parameters and ultrafiltration rate at baseline and during the study period. Briefly, while compared with baseline data, serum albumin significantly decreased after three years followup in both twice-weekly HD and thrice-weekly HD groups. The other variables were stable during followup. The table also indicated that twice-weekly HD had significantly lower hemoglobin and weekly SpKt/V, but higher serum creatinine and SpKt/V compared with thriceweekly HD in most study time points.

5 patients in twice-
Kidney Blood Press Res 2018;43:1104-1112

\begin{tabular}{l|l}
\hline DOI: $10.1159 / 000491566$ & C 2018 The Author(s). Published by S. Karger AG, Base
\end{tabular}

Published online: 9 July, 2018 www.karger.com/kbr
Table 2. Baseline data of 62 patients more than 10 years HD vintage grouped according to dialysis frequency. Note: Data are expressed as mean $\pm S D, P$ values result from comparisons of baseline values of the two groups divided by HD frequency. Abbreviations: BP, blood pressure; Scr, Serum creatinine; UF, ultrafiltration; SpKt/V, single-pool $\mathrm{Kt} / \mathrm{V}$; URR, urea reduction ratio; iPTH, intact parathyroid hormone

\begin{tabular}{lcccc}
\hline Characteristics & All Patients & $\begin{array}{c}\text { Twice-weekly } \\
\text { HD }\end{array}$ & Thrice-weekly HD & P Value \\
\hline No. of patients & 62 & 15 & 47 & \\
Gender M:F & $35: 27$ & $8: 7$ & $27: 20$ & \\
Age years & $58.6 \pm 11.1$ & $58.5 \pm 10.4$ & $58.6 \pm 11.4$ & 0.990 \\
HD vintage years & $14.7 \pm 3.2$ & $13.8 \pm 4.3$ & $15.0 \pm 2.8$ & 0.213 \\
Body mass index kg/m ${ }^{2}$ & $22.8 \pm 2.9$ & $22.3 \pm 2.7$ & $23.0 \pm 2.9$ & 0.423 \\
Systolic BP mmHg & $136.5 \pm 22.0$ & $144.2 \pm 23.9$ & $134.1 \pm 21.1$ & 0.122 \\
Diastolic BP mmHg & $74.2 \pm 13.5$ & $74.9 \pm 15.5$ & $74.0 \pm 12.9$ & 0.826 \\
Blood urea nitrogen mmol/L & $28.2 \pm 6.8$ & $32.2 \pm 5.7$ & $26.9 \pm 6.6$ & 0.007 \\
Scr umol/L & $1037.1 \pm 212.0$ & $1213.2 \pm 260.8$ & $980.9 \pm 160.0$ & 0.000 \\
SpKt/V & $1.92 \pm 0.32$ & $2.13 \pm 0.31$ & $1.86 \pm 0.30$ & 0.004 \\
URR \% & $78.3 \pm 5.4$ & $81.0 \pm 4.4$ & $77.4 \pm 5.5$ & 0.024 \\
Weekly SpKt/V & $5.25 \pm 1.00$ & $4.25 \pm 0.62$ & $5.57 \pm 0.90$ & 0.000 \\
HD session time hours & $4.32 \pm 0.44$ & $4.73 \pm 0.46$ & $4.19 \pm 0.34$ & 0.000 \\
UF rate L/per session & $3.25 \pm 0.92$ & $3.51 \pm 1.01$ & $3.16 \pm 0.88$ & 0.203 \\
Hemoglobin g/L & $115.6 \pm 16.6$ & $110.4 \pm 15.7$ & $117.3 \pm 16.7$ & 0.163 \\
Serum albumin g/l & $38.6 \pm 3.4$ & $38.7 \pm 2.8$ & $38.6 \pm 3.6$ & 0.941 \\
Calcium mmol/L & $2.22 \pm 0.34$ & $2.23 \pm 0.31$ & $2.22 \pm 0.36$ & 0.901 \\
Phosphorus mmol/L & $1.80 \pm 0.56$ & $2.04 \pm 0.43$ & $1.726 \pm 0.57$ & 0.055 \\
iPTH pg/ml & $633.8 \pm 565.1$ & $758.5 \pm 711.3$ & $594.0 \pm 512.7$ & 0.330 \\
\hline
\end{tabular}

Table 3. Longitudinal data of 106 HD-patients more than 5 years HD vintage during the study period. Note: Data are expressed as mean $\pm \mathrm{SD}$, $\mathrm{P}$ values result from comparisons of the two groups divided by HD frequency at different study point. Abbreviations: Scr, Serum creatinine; UF, ultrafiltration; SpKt/V, single-pool Kt/V. ${ }^{*} \mathrm{P}<0.01$, compared with twice-weekly HD, ANOVA; ${ }^{\Delta} \mathrm{P}<0.05$, compared with twice-weekly HD, ANOVA; ${ }^{\circ} \mathrm{P}<0.05$, compared with baseline, ANOVA; ${ }^{\star} \mathrm{P}<0.01$, compared with one year data, ANOVA

\begin{tabular}{lcccc}
\hline \multirow{2}{*}{ Characteristics } & \multicolumn{4}{c}{ Follow-Up } \\
& Baseline & One year & Two year & Three year \\
\hline No. of patients & 106 & 97 & 83 & 79 \\
Twice-weekly HD & 38 & 33 & 27 & 26 \\
Thrice-weekly HD & 68 & 64 & 56 & 53 \\
Hemoglobin g/L & $112.8 \pm 16.4$ & $112.0 \pm 15.6$ & $110.5 \pm 17.5$ & $112.3 \pm 16.9$ \\
Twice-weekly HD & $109.2 \pm 15.7$ & $105.8 \pm 14.3$ & $102.7 \pm 16.9$ & $103.8 \pm 13.0$ \\
Thrice-weekly HD & $114.8 \pm 16.6$ & $115.2 \pm 15.4^{*}$ & $114.3 \pm 16.6^{*}$ & $116.4 \pm 17.1^{*}$ \\
Serum albumin g/l & $38.9 \pm 3.2$ & $39.8 \pm 3.1$ & $38.5 \pm 2.8$ & $37.1 \pm 3.0^{\diamond \star}$ \\
Twice-weekly HD & $39.2 \pm 3.0$ & $40.0 \pm 3.5$ & $38.7 \pm 2.9$ & $36.4 \pm 3.5^{\diamond \star}$ \\
Thrice-weekly HD & $38.7 \pm 3.3$ & $39.7 \pm 2.9$ & $38.4 \pm 2.7$ & $37.4 \pm 2.6^{0 *}$ \\
Scr umol/L & $1040.8 \pm 221.3$ & $1048.0 \pm 239.9$ & $1075.7 \pm 266.7$ & $1003.3 \pm 245.0$ \\
Twice-weekly HD & $1114.3 \pm 287.0$ & $1131.0 \pm 285.2$ & $1163.7 \pm 323.9$ & $1039.4 \pm 289.2$ \\
Thrice-weekly HD & $999.7 \pm 162.7$ & $1005.2 \pm 202.2^{\Delta}$ & $1033.2 \pm 225.4^{\Delta}$ & $985.5 \pm 221.1$ \\
SpKt/V & $1.93 \pm 0.33$ & $1.93 \pm 0.37$ & $1.99 \pm 0.37$ & $1.85 \pm 0.33$ \\
Twice-weekly HD & $2.12 \pm 0.31$ & $2.15 \pm 0.36$ & $2.19 \pm 0.33$ & $1.96 \pm 0.30$ \\
Thrice-weekly HD & $1.83 \pm 0.30^{*}$ & $1.81 \pm 0.31^{*}$ & $1.89 \pm 0.35^{*}$ & $1.80 \pm 0.33^{\star}$ \\
UF L/per session & $3.11 \pm 0.91$ & $3.26 \pm 0.90$ & $3.24 \pm 0.96$ & $3.22 \pm 0.92$ \\
Twice-weekly HD & $3.24 \pm 0.96$ & $3.48 \pm 0.97$ & $3.46 \pm 1.10$ & $3.23 \pm 1.01$ \\
Thrice-weekly HD & $3.04 \pm 0.88$ & $3.15 \pm 0.85$ & $3.14 \pm 0.87$ & $3.21 \pm 0.89$ \\
Weekly SpKt/V & $5.03 \pm 1.01$ & $5.05 \pm 1.02$ & $5.26 \pm 1.11$ & $4.91 \pm 1.12$ \\
Twice-weekly HD & $4.23 \pm 0.63$ & $4.30 \pm 0.73$ & $4.38 \pm 0.66$ & $3.93 \pm 0.60$ \\
Thrice-weekly HD & $5.48 \pm 0.90^{*}$ & $5.44 \pm 0.93^{*}$ & $5.68 \pm 1.04^{*}$ & $5.40 \pm 0.99^{*}$ \\
Phosphorus mmol/L & $1.81 \pm 0.51$ & $1.87 \pm 0.53$ & $1.96 \pm 0.51$ & $1.78 \pm 0.53$ \\
Twice-weekly HD & $1.90 \pm 0.46$ & $1.91 \pm 0.55$ & $1.84 \pm 0.38$ & $1.69 \pm 0.51$ \\
Thrice-weekly HD & $1.77 \pm 0.54$ & $1.85 \pm 0.52$ & $2.02 \pm 0.56$ & $1.82 \pm 0.54$ \\
\hline
\end{tabular}

weekly HD group had obvious urine output initially but 3 of them became anuric when the study ended.

4 patients switched from twice-weekly HD to thrice-weekly HD during the follow-up, the reason for dialysis frequency alteration was due to suspected overhydration. 


\section{Kidney \\ Blood Pressure Research}

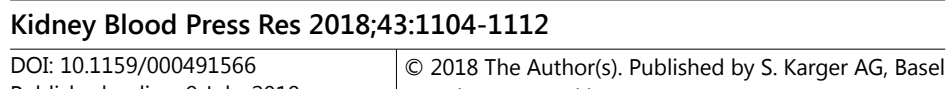

Published online: 9 July, 2018 www.karger.com/kbr

Lin et al.: Twice-Weekly Hemodialysis

Table 4. Relative risk (RR) of death in univariate Cox regression for selected variables at baseline in 106 HD-patients more than 5 years HD vintage. Abbreviations: BP, blood pressure; UF, ultrafiltration; iPTH, intact parathyroid hormone

\begin{tabular}{lccc}
\hline Variables & $\begin{array}{c}\text { Odds Ratio } \\
95 \%\end{array}$ & $\begin{array}{c}\text { Confidence } \\
\text { Interval }\end{array}$ & $\begin{array}{c}\text { P } \\
\text { Value }\end{array}$ \\
\hline Age 1year & 1.077 & $1.034-1.121$ & 0.000 \\
Sex male & 0.714 & $0.282-1.808$ & 0.477 \\
Body mass index 1kg/m² & 1.102 & $0.964-1.261$ & 0.156 \\
HD vintage 1years & 0.972 & $0.880-1.074$ & 0.574 \\
Diabetic status present & 2.963 & $1.056-8.314$ & 0.039 \\
Twice-weekly HD vs. & 0.990 & $0.371-2.638$ & 0.983 \\
Thrice-weekly HD & 1.032 & $0.778-1.367$ & 0.828 \\
Hemoglobin 1g/L & 0.942 & $0.817-1.085$ & 0.406 \\
Calcium 0.1mmol/L & 0.996 & $0.905-1.097$ & 0.937 \\
Phosphorus 0.1mmol/L & 1.001 & $0.913-1.097$ & 0.988 \\
iPTH 100pg/ml & 0.703 & $0.598-0.826$ & 0.000 \\
Serum albumin 1 g/L & 0.928 & $0.861-1.000$ & 0.049 \\
Blood urea nitrogen 1mmol/L & 0.728 & $0.594-0.892$ & 0.002 \\
Serum creatinine 100umol/L & & $0.845-1.107$ & 0.627 \\
Single-pool Kt/V & 0.967 & & \\
0.1 unit/per sessio & & & \\
Weekly SpKt/V & 0.994 & $0.949-1.041$ & 0.792 \\
0.1 unit/per week & 0.955 & $0.909-1.003$ & 0.067 \\
UF rate 100ml/per session & 0.506 & $0.146-1.757$ & 0.283 \\
HD session time hours & 1.000 & $0.957-1.045$ & 0.991 \\
Dry weight 1 kg & 0.897 & $0.733-1.099$ & 0.295 \\
Systolic BP 10mmHg & 0.862 & $0.618-1.202$ & 0.381 \\
Diastolic BP 10mmHg & & & \\
\hline & & &
\end{tabular}

Table 5. Summary of step-wise Cox regression analysis of patient survival using time-dependent albumin. The original model included age, gender, diabetic status, time-dependent serum albumin,

\begin{tabular}{lccc}
\hline Variables & $\begin{array}{c}\text { Odds Ratio } \\
95 \%\end{array}$ & $\begin{array}{c}\text { Confidence } \\
\text { Interval }\end{array}$ & $\begin{array}{c}\mathrm{P} \\
\text { Value }\end{array}$ \\
\hline Age 1year & 1.050 & $1.008-1.094$ & 0.019 \\
Time-averaged Albumin $(\mathrm{t})$ & 0.743 & $0.640-0.863$ & 0.000 \\
$1 \mathrm{~g} / \mathrm{L}$ & & & \\
\hline
\end{tabular}
and dialysis frequency

\section{Survival analysis}

During the study period, 25 patients dropped-out. 3 were transferred to other hemodialysis centers, 2 received transplantation, and 20 died. Cardiovascular disease was the leading cause of death, while infection was the second most common cause of death.

Univariate Cox regression survival analysis was summarized in Table 4. Briefly, age, diabetic status, serum albumin, blood urea nitrogen, and serum creatinine were each predictors of death. In multivariate Cox analysis, age and time-dependent serum albumin were predictors of mortality, whereas hemodialysis frequency could not predict mortality (Table 5).

Kaplan-Meier survival analysis showed that the two groups between twice-weekly HD and thrice-weekly HD had similar survival (P=0.983) (Fig.1). Subgroup analysis of 62 patients with more than 10 years HD vintage also indicated that the two groups had similar survival( $\mathrm{P}=0.766$ ) (Fig.2).

There were 5 patients more than 20 years HD vintage ( 2 patients twice-weekly HD and 3 patients thrice-weekly HD), only one patient on thrice-weekly HD died during the study period and the other 4 patients were alive at the end of the study.

\section{Discussion}

Thrice-weekly hemodialysis has been the standard renal replacement therapy (RRT) for several decades, but twice-weekly HD is prevalent in the developing countries, and also could be found in American and in some European countries [1-3]. Thus far, there was no randomized controlled study to confirm that thrice-weekly HD was bound to superior to twice-weekly HD. In contrast, most observational studies indicated that twice-weekly HD had no inferior survival as compared with thrice-weekly HD. As far as 1999, data from the American national sample have found that twice-weekly HD had similar or even better survival compared to thrice-weekly HD either in prevalent patients or in incident patients [2]. Panaput 


\section{Kidney Blood Pressure Research}

Kidney Blood Press Res 2018;43:1104-1112

\begin{tabular}{l|l}
\hline DOI: $10.1159 / 000491566$ & (C) 2018 The Author(s). Published by S. Karger AG, Basel
\end{tabular}

Published online: 9 July, 2018 www.karger.com/kb

Lin et al.: Twice-Weekly Hemodialysis conducted a prospective multi-center cohort study in Thailand, the results indicated that survival rate and times to hospitalization between the two groups were similar [6]. We also reported that twice-weekly HD patients had no inferior survival as compared with thrice-weekly HD in Shanghai [11]. Moreover, several studies from Shanghai and Taiwan have demonstrated that patients on twice-weekly HD had a slower decline of RRF as compared with those on thrice-weekly HD [12, 13]. Hitherto, only very few limited data suggested that thrice-weekly HD might have better survival compared with twice-weekly HD. Obi performed a retrospective analysis of HD patients in the united states and found that patients on twice-weekly HD with little to no RRF experienced a higher all-cause mortality compared to those with similar low RRF on thrice-weekly HD, however, among patients with substantial RRF there was no difference in survival by dialysis frequency [7]. In a word, it showed that twice-weekly HD was not a repulsive RRT model for dialysis patients, both advantage and disadvantage should be considered when selected this treatment regime.

Being afraid of inadequate dialysis, previous guidelines on hemodialysis adequacy were based on thrice-weekly HD $[14,15]$. The 2006 KDOQI guidelines first set up an adequacy target for twice-weekly HD mainly according to experts' opinion [16]. Recently some experts have advised an incremental hemodialysis with initiation of twice-weekly HD for incident patients in order to preserve the residual renal function better and to maximize the use of medical resource [7-9], but it is unclear how long for this treatment approach could be lasted, and very scarce data are available for such dialysis regime in patients with long-term dialysis vintage.

In the present study, we firstly described the clinical features and outcomes of twiceweekly HD patients with long-term dialysis vintage, most of them were in anuric stage. It

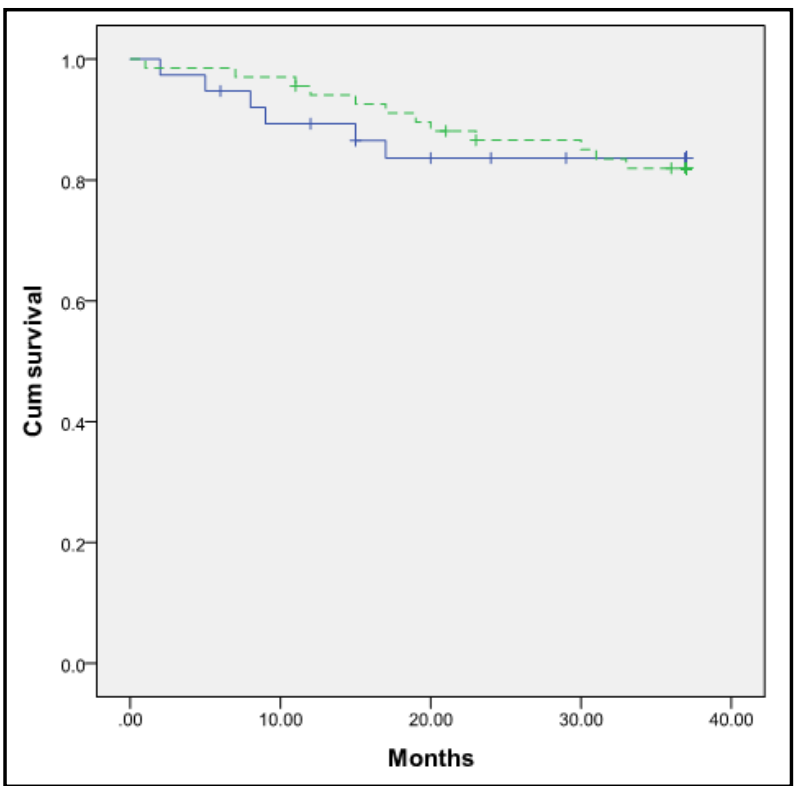

Fig. 1. Kaplan-Meier survival curves for all-cause mortality in 106 hemodialysis patients more than 5 years HD vintage grouped according to twice-weekly hemodialysis (solid) and thrice-weekly hemodialysis (dashed); $\mathrm{P}=0.983$.

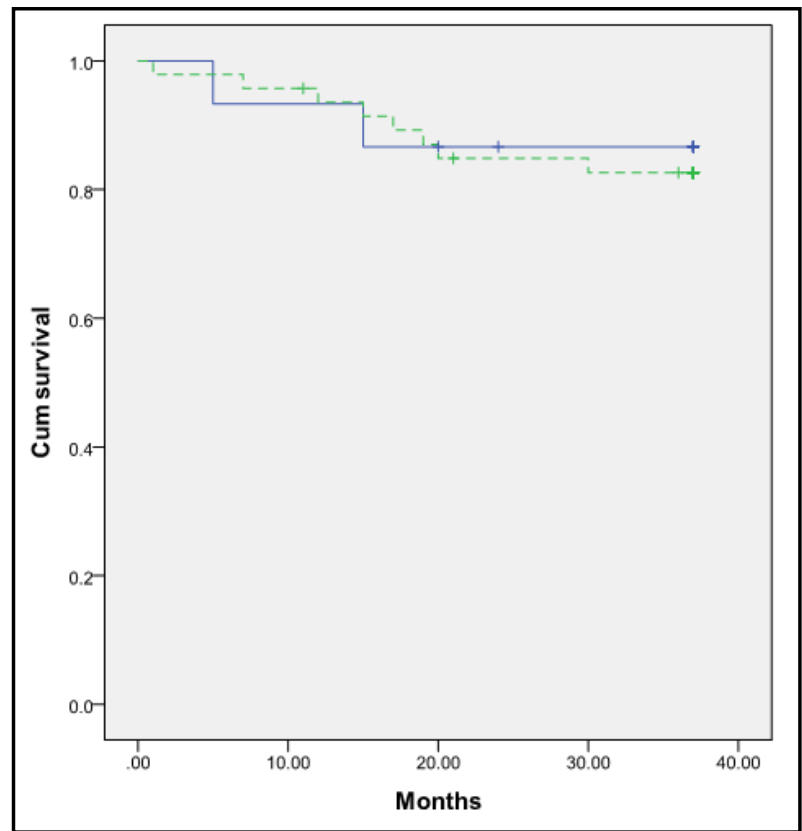

Fig. 2. Kaplan-Meier survival curves for all-cause mortality in 62 hemodialysis patients more than 10 years HD vintage grouped according to twice-weekly hemodialysis (solid) and thrice-weekly hemodialysis (dashed); $\mathrm{P}=0.766$. 


\section{Kidney Blood Pressure Research}

Kidney Blood Press Res 2018;43:1104-1112

\begin{tabular}{l|l}
\hline DOI: $10.1159 / 000491566$ & C 2018 The Author(s). Published by S. Karger AG, Base
\end{tabular}

Published online: 9 July, 2018

www.karger.com/kbr

Lin et al.: Twice-Weekly Hemodialysis

was unexpected to find that survival in twice-weekly HD patients, either in those more than 5 years HD vintage or in those more than 10 years HD vintage, was similar with that in thriceweekly HD patients. Moreover, 2 patients on twice-weekly HD have been more than 20 years HD vintage and they still kept well after 3 years follow-up. The longest vintage patient in the study was on twice-weekly HD with 24.9 years vintage at baseline, he absolutely refused to change to thrice-weekly HD as he felt well on twice-weekly HD, and he did have good life quality throughout the study. Taken together, our study demonstrated that at least some of twice-weekly HD patients could achieve no inferior survival as compared with thrice-weekly HD even with long-term dialysis vintage.

5 patients in twice-weekly HD group had obvious urine output at baseline and 2 of them still had urine output after 3 years follow-up, whereas none of the patients on thrice-weekly HD group had acceptable RRF. This result was coordinated with previous studies that twiceweekly HD preserved RRF better than thrice-weekly HD [12, 13]. Since RRF significantly impacted dialysis patients' outcomes, it is not surprise that twice-weekly HD could achieve similar or even better survival than thrice-weekly HD in incident patients with certain RRF. However, it would be confused that the present study indicated the similar survival between the two groups while most of the patients were in anuric stage. One reason is that we applied an incremental dialysis approach. It should be noticed that 4 patients with suspected fluid overload in twice-weekly HD group were transferred to thrice-weekly HD. one can speculate that some of patients with inadequate fluid and solute removal were gradually transferred from twice-weekly HD to thrice-weekly HD. Thus, the similar survival between twice-weekly HD and thrice-weekly HD in patients with long-term dialysis vintage is likely relating to patient selection.

Apart from RRF and incremental dialysis, there were several other factors may benefit twice-weekly HD in our study: First of all, a longer HD session time and a higher spKt/V in twice-weekly HD group was likely favoring this treatment selection, as previous studies have found that a longer HD session time and an adequacy of hemodialysis significantly benefited patients' outcomes $[17,18]$. Secondly, recent advance in hemodialysis may enable twiceweekly HD to maintain for a long-term dialysis vintage. Most patients in the study used Fresenius high flux dialyzers and all the patients used ultrapure dialysate, such conditions would ensure an optimal solute clearance and benefit both the twice-weekly HD and thriceweekly HD patients [19-21]. Thus, our unique twice-weekly HD model characterized as a longer HD session time, a higher spKt/V around 2.0, and using high flux dialyzers and a personalized incremental dialysis approach. To our knowledge, the effect of such unique twice-weekly HD practice has not been reported elsewhere.

Previous studies demonstrated that volume status significantly impacted the prognosis of ESRD patients both in hemodialysis patients and peritoneal dialysis patients [22-24].The similar ultrafiltration volume between the two groups implied that most of the patients with twice-weekly HD only have moderate interdialytic fluid accumulation, which was likely associated with a better life style in twice-weekly HD group, a strict restriction of sodium and fluid intake should be important for twice-weekly HD patients.

Many studies have found that albumin was a strong predictors for dialysis patients [25, 26]. Our study also confirmed that serum albumin, no matter baseline level or time-dependent one, could strongly predict the clinical outcome of hemodialysis patients. Apart from this, serum albumin significantly decreased with time in both twice-weekly HD and thrice-weekly HD groups. It was possible that malnutrition-inflammation-atherosclerosis(MIA) syndrome existed in our long term dialysis patient cohort, previous studies have demonstrated that this syndrome was associated with poor outcome in dialysis patients $[27,28]$.

The limitations of the present study include its design with a relatively small number of patients and the fact that it was not a randomized controlled trial. Besides, few patients had little urine output and we did not have definite RRF calculation of these patients. In spite of these shortcomings, we firstly reported the clinical features and outcomes of twice- 


\section{Kidney Bloód Pressure Research}

Lin et al.: Twice-Weekly Hemodialysis

weekly hemodialysis patients with long-term dialysis vintage, and it offers a new insight for individualized treatment of hemodialysis patients.

\section{Conclusion}

The similar survival between twice-weekly HD and thrice-weekly HD in patients with long-term dialysis vintage is meaningful for patients or units with financial constraints and resources limitations, but the results is likely relating to patient selection. A longer HD session time, a higher spKt/V, a close monitor and a personalized incremental dialysis should be important for this treatment regime. Individualized treatment for dialysis patients based on clinical features and socioeconomic factors remains a tough task for the clinicians.

\section{Acknowledgements}

We are grateful to all medical staff who participated in maintaining the routine dialysis database.

We appreciate professor Jiaqi Qian who first pointed out the important issue of twiceweekly hemodialysis practice in China.

This study was partly sponsored by Shanghai Pujiang Program 16PJ1405900.

\section{Disclosure Statement}

All authors declare that there is no conflict of interest related to this paper.

\section{References}

1 Couchoud C, Kooman J, Finne P, Leivestad T, Stojceva-Taneva O, Ponikvar JB, Collart F, Kramar R, de Francisco A, Jager KJ, Quality European Studies Working Group on Dialysis Adequacy: From registry data collection to international comparisons: examples of haemodialysis duration and frequency. Nephrol Dial Transplant 2009;24:217-224.

$\longrightarrow 2$ Hanson JA, Hulbert-Shearon TE, Ojo AO, Port FK, Wolfe RA, Agodoa LY, Daugirdas JT: Prescription of TwiceWeekly Hemodialysis in the USA. Am J Nephrol 1999;19:625-633.

- G Ghahremani-Ghajar M, Rojas-Bautista V, Lau WL, Pahl M, Hernandez M, Jin A, Reddy U, Chou J, Obi Y, Kalantar-Zadeh K, Rhee CM: Incremental Hemodialysis: The University of California Irvine Experience. Semin Dial 2017;30:262-269.

4 Bieber B, Qian J, Anand S, Yan Y, Chen N, Wang M, Wang M, Zuo L, Hou FF, Pisoni RL, Robinson BM, Ramirez SP:Two-times weekly hemodialysis in China: frequency, associated patient and treatment characteristics and Quality of Life in the China Dialysis Outcomes and Practice Patterns study. Nephrol Dial Transplant 2014;29:1770-1777.

5 Rhee CM, Unruh M, Chen J, Kovesdy CP, Zager P, Kalantar-Zadeh K: Infrequent dialysis: a new paradigm for hemodialysis initiation. Semin Dial 2013;26:720-727.

-6 Panaput T, Thinkhamrop B, Domrongkitchaiporn S, Sirivongs D, Praderm L, Anukulanantachai J, Kanokkantapong C, Tungkasereerak P, Pongskul C, Anutrakulchai S, Keobounma T, Narenpitak S, Intarawongchot P, Suwattanasin A, Tatiyanupanwong S, Niwattayakul K: Dialysis dose and risk factors for death among ESRD patients treated with twice-weekly hemodialysis: a prospective cohort study. Blood Purif 2014;38:253-262.

7 Obi Y, Streja E, Rhee CM, Ravel V, Amin AN, Cupisti A, Chen J, Mathew AT, Kovesdy CP, Mehrotra R, KalantarZadeh K: Incremental hemodialysis, residual kidney function, and mortality risk in incident dialysis patients: a cohort study. Am J Kidney Dis 2016;68:256-265. 


\section{Kidney \\ Blood Pressure Research}

8 Kalantar-Zadeh K, Unruh M, Zager PG, Kovesdy CP, Bargman JM, Chen J, Sankarasubbaiyan S, Shah G, Golper T, Sherman RA, Goldfarb DS: Twice-weekly and incremental hemodialysis treatment for initiation of kidney replacement therapy. Am J Kidney Dis 2014;64:181-186.

-9 Merino JL, Domínguez P, Bueno B, Amézquita Y, Espejo B, Paraíso V: Application of a pattern of incremental haemodialysis, based on residual renal function, when starting renal replacement therapy. Nefrologia 2017;37:39-46.

10 Daugirdas JT: Second generation logarithmic estimates of single-pool variable volume Kt/V: an analysis of error. J Am Soc Nephrol 1993;4:1205-1213.

11 Lin X, Yan Y, Ni Z, Gu L, Zhu M, Dai H, Zhang W, Qian J: Clinical outcome of twice-weekly hemodialysis patients in shanghai. Blood Purif 2012,33:66-72.

12 Zhang M, Wang M, Li H, Yu P, Yuan L, Hao C, Chen J, Kalantar-Zadeh K: Association of initial twice-weekly hemodialysis treatment with preservation of residual kidney function in ESRD patients. Am J Nephrol 2014;40:140-150.

13 Lin YF, Huang JW, Wu MS, Chu TS, Lin SL, Chen YM, Tsai TJ, Wu KD: Comparison of residual renal function in patients undergoing twice-weekly versus three-times-weekly hemodialysis. Nephrology 2009;14:59-64.

14 NKF-K/DOQI Clinical Practice Guidelines for Hemodialysis Adequacy: update 2000. Am J Kidney Dis 2001;37:S7-S64.

15 European Best Practice Guidelines Expert Group on Hemodialysis, European Renal Association: Section II. Hemodialysis adequacy. Nephrol Dial Transplant 2002;17:S16-S31.

16 Hemodialysis Adequacy 2006 Work Group: Clinical practice guidelines for hemodialysis adequacy, update 2006. Am J Kidney Dis 2006;48:S2-S90.

17 Charra B, Calemard E, Ruffet M, Chazot C, Terrat JC, Vanel T, Laurent G: Survival as an index of adequacy of dialysis. Kidney Int 1992;41:1286-1291.

>18 Held PJ, Port FK, Wolfe RA, Stannard DC, Carroll CE, Daugirdas JT, Bloembergen WE, Greer JW, Hakim RM: The dose of hemodialysis and patient mortality. Kidney Int 1996;50:550-556.

19 Susantitaphong P, Riella C, Jaber BL: Effect of ultrapure dialysate on markers of inflammation, oxidative stress, nutrition and anemia parameters: a meta-analysis. Nephrol Dial Transplant 2013;28:438-446.

20 Kim HW, Kim SH, Kim YO, Jin DC, Song HC, Choi EJ, Kim YL, Kim YS, Kang SW, Kim NH, Yang CW, Kim YK: Comparison of the impact of high-flux dialysis on mortality in hemodialysis patients with and without residualrenal function. PLoS One 2014;9:e97184.

21 Asci G, Tz H, Ozkahya M, Duman S, Demirci MS, Cirit M, Sipahi S, Dheir H, Bozkurt D, Kircelli F, Ok ES, Erten S, Ertilav M, Kose T, Basci A, Raimann JG, Levin NW, Ok E; EGE Study Group: The impact of membrane permeability and dialysate purity on cardiovascular outcomes. J Am Soc Nephrol 2013;24:1014-1023.

-22 Ateş K, Nergizoğlu G, Keven K, Sen A, Kutlay S, Ertürk S, Duman N, Karatan O, Ertuğ AE: Effect of fluid and sodium removal on mortality in peritoneal dialysis patients. Kidney Int 2001;60:767-776.

-23 Wizemann V, Wabel P, Chamney P, Zaluska W, Moissl U, Rode C, Malecka-Masalska T, Marcelli D: The mortality risk of overhydration in hemodialysis patients. Nephrol Dial Transplant 2009;16:1574-1579.

$\checkmark 24$ Onofriescu M, Hogas S, Voroneanu L, Apetrii M, Nistor I, Kanbay M, Covic AC: Bioimpedance-guided fluid management in maintenance hemodialysis: a pilot randomized controlled trial. Am J Kidney Dis. 2014;64:111-118.

25 Malgorzewicz S, Chmielewski M, Kaczkan M, Borek P, Lichodziejewska-Niemierko M, Rutkowski B: Nutritional predictors of mortality in prevalent peritoneal dialysis patients. Acta Biochim Pol 2016;63:111115.

26 Lin X, Lin A, Ni Z, Yao Q, Zhang W, Yan Y, Fang W, Gu A, Axelsson J, Qian J: Daily peritoneal ultrafiltration predicts patient and technique survival in anuric peritoneal dialysis patients. Nephrol Dial Transplant 2010;25:2322-2327.

27 Sueta D, Hokimoto S, Sakamoto K, Akasaka T, Tabata N, Kaikita K, Honda O, Naruse M, Ogawa H; Multicenter Study of Hemodialysis Patients Undergoing Invasive Cardiovascular Procedures Study Investigators: Validation of the high mortality rate of Malnutrition-Inflammation-Atherosclerosis syndrome: -Communitybased observational study. Int J Cardiol 2017;230:97-102.

-28 Zyga S, Christopoulou G, Malliarou M: Malnutrition-inflammation-atherosclerosis syndrome in patients with end-stage renal disease. J Ren Care 2011;37:12-15. 